\title{
Green tea induces annexin-I expression in human lung adenocarcinoma A549 cells: involvement of annexin-I in actin remodeling
}

\author{
Qing-Yi Lu', Yu Sheng Jin², Zuo-Feng Zhang ${ }^{3}$, Anh D Le ${ }^{4}$, David Heber ${ }^{1}$, Frederick P Li ${ }^{5}$, Steven M Dubinett ${ }^{6}$ \\ and Jian Yu Rao 2,3
}

Green tea polyphenols exhibit multiple antitumor activities in various in vitro and in vivo tumor models, and the mechanisms of action are not clear. Previously, we found that green tea extract (GTE) regulates actin remodeling in different cell culture systems. Actin remodeling plays an important role in cancer cell morphology, cell adhesion, motility, and invasion. Using proteomic approaches, we found GTE-induced expression of annexin-I, a multifunctional actin binding protein, in these cell lines. In this study, we aimed to further define the functional role of GTE-induced annexin-I expression in actin remodeling, cell adhesion, and motility in lung adenocarcinoma A549 cells. We found that GTE stimulates the expression of annexin-I in a dose-dependent fashion. The GTE-induced annexin-I expression appears to be at the transcription level, and the increased annexin-I expression mediates actin polymerization, resulting in enhanced cell adhesion and decreased motility. Annexin-I specific interference resulted in loss of GTE-induced actin polymerization and cell adhesion, but not motility. In fact, annexin-I specific interference itself inhibited motility even without GTE. Together, annexin-I plays an important role in GTE-induced actin remodeling, and it may serve as a potential molecular target associated with the anticancer activities of green tea.

Laboratory Investigation (2007) 87, 456-465. doi:10.1038/labinvest.3700534; published online 12 March 2007

KEYWORDS: annexin-l; cell migration; F-actin; green tea; lung adenocacinoma; chemoprevention

Lung cancer is the most common leading cause of cancerrelated death in the US, with an estimated 162246 deaths in 2006. The 5-year relative survival rate for all stages combined is $15 \%{ }^{1}$ Non-small-cell lung cancer is the most common type of lung cancer, and adenocarcinoma including bronchioloaveolar accounts for $40 \%$ of non-small-cell lung cancer. Tobacco smoking is a leading risk factor for the development of all lung cancer types. Although smoking cessation has been shown to be an effective primary preventive method, an intensive effort has also been devoted to developing chemopreventive strategies for lung cancer. However, previous randomized controlled trials of $\beta$-carotene, $\alpha$-tocopherol, retinal, retinyl palmitate, $N$-acetylcysteine, and isotretinoin have not been successful in demonstrating any preventive effects in smokers. ${ }^{2,3}$ Therefore, novel chemopreventive agents with pathway-specific effects will need to be developed and validated for future trials.

Green tea (Camellia sinensis leaves) contains polyphenols that are naturally occurring antioxidants and is a potentially promising chemopreventive agent. ${ }^{4}$ Tea is one of the most popular drinks worldwide. Green tea accounts for approximately $20 \%$ of tea consumption in the world. The active constituents of green tea are polyphenols, also called tea catechins (3-flavanols), including (-)-epicatechin, (-)-epigallocatechin, (-)-epicatechin gallate, and (-)-epigallocatechin gallate (EGCG). Among these constituents, EGCG is the most abundant. Studies on the mechanisms of the chemoprevention of green tea in various cell lines revealed that tea may contribute to the inhibition of the formation/activation of carcinogens, modulation of signal transduction pathways

\footnotetext{
${ }^{1}$ Department of Medicine, Center for Human Nutrition, University of California at Los Angeles, Los Angeles, CA, USA; ${ }^{2}$ Department of Pathology and Laboratory Medicine, University of California at Los Angeles, Los Angeles, CA, USA; ${ }^{3}$ Department of Epidemiology, University of California at Los Angeles, Los Angeles, CA, USA: ${ }^{4}$ Center for Craniofacial Molecular Biology, School of Dentistry, Center for Craniofacial Molecular Biology, University of Southern California, Los Angeles, CA, USA; ${ }^{5}$ Department of Medicine, Dana-Farber Cancer Institute, Boston, MA, USA and ${ }^{6}$ Department of Medicine, University of California at Los Angeles, Los Angeles, CA, USA Correspondence: DR JY Rao, MD, Department of Pathology and Laboratory Medicine, University of California at Los Angeles, 10833 LeConte Ave, Box 951732 , Los Angeles, CA 90095-1732, USA. E-mail: jrao@mednet.ucla.edu
} 
that lead to the inhibition of cell proliferation and transformation, induction of apoptosis of preneoplastic and neoplastic cells, inhibition of tumor invasion and angiogenesis, and inhibition of COX-2 activity. ${ }^{4-6}$ In animal models, inhibition of tumorigenesis by green tea has been demonstrated in different organ sites including the lung. Several studies showed that green tea extract (GTE) given as a source of drinking water to rats inhibited the lung tumorigenesis induced by smoke carcinogens, NDEA ( $N$-nitrosodiethylamine), NNK (4-(methylnitrosamino)-1-(3-pyridyl)1-butanone), and MNNG ( $N$-methyl- $N^{\prime}$-nitro- $N$-nitrosoguanidine) at the initiation and progression stages and inhibited the spontaneous formation of lung tumors (see review article Yang et $a l^{6}$ ). Although animal studies have reported compelling results on the chemopreventive effects of green tea in lung cancer, human population-based studies have produced inconsistent findings. Some have found that green tea consumption is either associated with an increased ${ }^{7}$ or reduced risk ${ }^{8-10}$ of lung cancer, whereas others have found no effect. ${ }^{11-13}$

In our previous studies, we have shown that GTE induces actin remodeling in transformed urothelial MC-T11 cells, antagonizes cigarette carcinogen 4-aminobiphenyl induced actin depolymerization in untransformed HUC-PC cells, and inhibits 4-aminobiphenyl induced motility in transformed MTC-11 cells using a unique in vitro bladder cancer carcinogenesis model. ${ }^{14}$ The dynamics of actin remodeling plays an important role in regulating phenotypic changes of premalignant and malignant cells, such as altered morphology, tumor invasion, and altered growth and apoptosis control. Using a proteomic approach, we recently identified a GTE induced actin-binding protein, annexin-I, in human urothelial MC-T11 cells ${ }^{15}$ and lung adenocarcinoma A549 cells. Annexin-I was found to be associated with GTE-induced actin remodeling in MC-T11 cells. Annexin-I (lipocortin-1) was originally identified as a glucocorticoid-inducible $37 \mathrm{kDa}$ protein and is expressed in epithelial cells. ${ }^{16}$ Previous studies have reported that annexin-I expression is associated with glucocorticoid-induced antiproliferative effects in A549 cells. ${ }^{17}$ To investigate further the functional consequences of annexin-I upregulation, we have undertaken this study to focus on the investigation of the relationship between GTEinduced annexin-I expression and actin remodeling in A549 cells. Our data show that GTE-induced annexin-I upregulation is dose-dependent and occurs at transcriptional level, and increased expression of annexin-I correlates with the stimulation of filamentous-actin (F-actin) polymerization and the enhancement of cell adhesion. The results of the study provide further support for green tea-based chemoprevention.

\section{MATERIALS AND METHODS Materials}

GTE was obtained from Pharmanex Inc. (Provo, UT, USA). The purity of the catechins in the GTE was $84 \% .{ }^{14}$ The
Pharmanex GTE consisted of a mixture of many catechin compounds, with EGCG as a major component $(43.0 \%$ by weight), followed by epicatechin-3-gallate $(13.7 \%)$, epicatechin $(6.0 \%)$, gallocatechin gallate $(5.6 \%)$, epigallocatechin $(4.0 \%)$, gallocatechin $(2.3 \%)$, catechin $(2.0 \%)$, and catechin gallate $(1.4 \%)$. The GTE contains less than $0.3 \%$ caffeine. In this study, the concentration was expressed as the amount of GTE per milliliter of media bathing the cells $(\mu \mathrm{g} / \mathrm{ml})$.

\section{Cell Culture and GTE Stimulation}

Human lung adenocarcinoma A549 cell line, large cell lung carcinoma NCI-H460 cell line (American Type Culture Collection, Rockville, MD, USA) and squamous cell carcinoma NCI-H157 cell line (National Cancer Institute, Bethesda, MD, USA) were grown in 90\% RPMI 1640 (Mediatech Inc., Herndon, VA, USA) medium with $1 \%$ penicillin and streptomycin mix solution (Invitrogen Corporation, Carlsbad, CA, USA) and $10 \%$ fetal bovine serum (FBS). Cultures were maintained at $37^{\circ} \mathrm{C}$ in $5 \% \mathrm{CO}_{2}$ and $95 \%$ air, and the medium changed two times per week. GTE was dissolved in double-distilled $\mathrm{H}_{2} \mathrm{O}$ to make a stock solution of $10 \mathrm{mg} / \mathrm{ml}$. Logarithmically growing A549 cells were harvested and seeded at an initial density of $1 \times 10^{6}$ cells in $5 \mathrm{ml}$ of fresh medium in $60-\mathrm{mm}$ Petri dishes. After overnight proliferation, the adherent cells were incubated with GTE at final concentrations of $0,10,20,40,80$, and $160 \mu \mathrm{g} / \mathrm{ml}$ for different time points $(0,24,48$, and $72 \mathrm{~h})$. The final solvent concentrations in the medium were less than $0.1 \%(\mathrm{v} / \mathrm{v})$, which had minimum effect on the cells. At the end of each treatment, cells were harvested and centrifuged at 2000 r.p.m. for $5 \mathrm{~min}$.

\section{Immunoblot Analysis}

Cells that were washed two times in cold PBS were scraped from culture dishes in lysis buffer ( $50 \mathrm{mM}$ Tris- $\mathrm{HCl}(\mathrm{pH} 7.4)$, $150 \mathrm{mM} \mathrm{NaCl}, 2 \mathrm{mM}$ EGTA, $2 \mathrm{mM} \mathrm{MgCl}_{2}, 1 \%$ (v/v) Triton X-100, $10 \%$ glycerol, $10 \mathrm{mM}$ DTT, $1 \mathrm{mM}$ phenylmethylsulfonyl fluoride, $10 \mu \mathrm{g} / \mathrm{ml}$ leupeptin, $10 \mu \mathrm{g} / \mathrm{ml}$ aprotinin, $5 \mu \mathrm{g} / \mathrm{ml}$ pepstatin $\mathrm{A}, 50 \mathrm{mM} \mathrm{NaF}$, and $1 \mathrm{mM}$ $\mathrm{NaV}_{3} \mathrm{O}_{4}$ ). Lysates were incubated at $4^{\circ} \mathrm{C}$ for $30 \mathrm{~min}$ and then centrifuged at $12000 \mathrm{~g}$ and $4^{\circ} \mathrm{C}$ for $10 \mathrm{~min}$. Protein concentrations of lysates were determined by the Bio-Rad Protein Assay (Bio-Rad Laboratories, Hercules, CA, USA). For Immunoblot analyses, the same amount of proteins (30 or $50 \mu \mathrm{g})$ was subjected to $8 \%$ SDS-PAGE and was electrotransferred to nitrocellulose membranes. Membranes were blocked in TBST containing 5\% non-fat dry milk for $30 \mathrm{~min}$. Reactions with the primary antibody (annexin-I, 1:5000, BD Biosciences Inc., San Jose, CA, USA), or $\beta$-actin (1:500, Sigma Chemical, St Louis, MO, USA) in TBST buffer containing $3 \%$ dry milk were carried out at $4^{\circ} \mathrm{C}$ overnight. After extensive washing, membranes were placed on a shaker with biotinylated secondary IgG for $1 \mathrm{~h}$. Upon further washing, membranes were reacted with enhanced chemiluminescence detection reagents (Amersham Biosciences, Piscataway, NJ, 
USA) immediately before autoradiography. The relative levels of annexin-I protein were determined by scanning densitometry using Alphalmager 2000 software (Alpha Innotech, Cannock, UK).

\section{Immunofluorescence Assay and Laser Scanning Cytometry Analysis}

For fluorescence analysis, cells cultured directly on a $1 \mathrm{~cm}$ diameter cover glass were fixed with $3.7 \%$ paraformaldehyde for $30 \mathrm{~min}$ and subjected for triple labeling of either F-actin/ annexin-I/DNA. A549 cells were incubated with 1:3000 mouse monoclonal anti-annexin-I (BD Biosciences) for $1 \mathrm{~h}$, 1:500 Cy3-conjugated AffiniPure Goat Anti-Mouse IgG $(\mathrm{H}+\mathrm{L}$ ) (Jackson ImmunoResearch Lab, West Grove, PA, USA) for $30 \mathrm{~min}$, 1:40 Bodipy phallacidin for F-actin (Molecular Probes Inc., Eugene, OR, USA) for $30 \mathrm{~min}, 1: 10000$ dilution of 4',6-diamidino-2-phenylindole (DAPI) stock solution for $5 \mathrm{~min}$. For paxillin, cells were incubated with 1:100 monoclonal anti-Paxillin (clone 5H11, Upstate Biotechnology, Lake Placid, NY, USA) for $1 \mathrm{~h}$. For triple labeling of Factin/G-actin/DNA, cells were incubated sequentially with 1:150 Alexa Fluor 647-conjugated DNase I (Molecular Probes) for $30 \mathrm{~min}, 100 \mu \mathrm{l}$ of Bodipy conjugated phalloidin (Molecular Probes, 1:200 v/v) for another $30 \mathrm{~min}$, and 1:1000 dilution of $4^{\prime}, 6$-diamidino-2-phenylindole $(10 \mathrm{mg} / \mathrm{ml}$, Molecular Probes) for $5 \mathrm{~min}$. In between each incubation step, the cover glass was rinsed with cold PBS three times. The stained cover glass was then transferred onto a regular microscopic slide, which was then mounted in PermaFluor Mountant medium (Thermo Electron Corp., Pittsburgh, PA, USA) for the fluorescence microscopic examination. Images were generated using a Nikon TE300 microscope equipped with an Imaging Microimager II digital camera. F-actin fluorescence intensity was also analyzed using laser scanning cytometer (LSC) (CompuCyte, Cambridge, MA, USA) using method described previously. ${ }^{14}$

\section{RNA Extraction and Quantitative Real-Time RT-PCR}

Total RNA was extracted from GTE treated or untreated A549 cells using a TRIzol reagent (Life Technologies, Grand Island, NY, USA), and purified using the RNeasy Mini Kit (Qiagen, Valencia, CA, USA). The first-stand cDNA was synthesized using $2 \mu \mathrm{g}$ of total RNA in a $20 \mu \mathrm{l}$ reverse transcriptase reaction mixture: $2 \mu \mathrm{g}$ of total RNA, $2 \mu \mathrm{l}(10 \mu \mathrm{M})$ of Oligo$(\mathrm{dT})_{12-18}, 1 \mu \mathrm{l}(10 \mathrm{U} / \mu \mathrm{l})$ of RNase inhibitor, $2 \mu \mathrm{l}(5 \mathrm{mM})$ of dNTP, and $1 \mu \mathrm{l}$ Omniscript enzyme (4 units/ $\mu \mathrm{l}$ ) from the RT Kit (Qiagen). All real-time PCR reactions were performed in a $20 \mu \mathrm{l}$ mixture containing $1 \mu \mathrm{l} \mathrm{cDNA}$ and $1 \times \mathrm{iQ}$ SYBR Grenne supermix (Bio-Rad Laboratory) using the iCycle iQ system (Bio-Rad Laboratory). The primers for PCR were designed based on GenBank for annexin A1 (annexin-I) mRNA sequences NM_000700, ${ }^{18}$ and $\beta$-actin mRNA sequences CR608667. ${ }^{19}$ The primer sequences for $\beta$-actin was sense, $5^{\prime}$-GTACCACTGGCATCGTGAT- ${ }^{\prime}$, antisense: $5^{\prime}$-ATCTTCATGAGGTAGTCAGTCA-3'. The primer se- quence for annexin-I was: sense, 5'-AAAGGTGGTCCCGG ATCAAG- $3^{\prime}$, antisense, $5^{\prime}$-TTATGCAAGGCAGCGACATC- $3^{\prime}$. The following PCR amplification parameters were used: $5 \mathrm{~min}$ at $95^{\circ} \mathrm{C}$ followed by 35 cycles of $95^{\circ} \mathrm{C}$ for $15 \mathrm{~s}$ and $60^{\circ} \mathrm{C}$ for $1 \mathrm{~min}$. Data acquisition was set at the chain extension step and the melt curve data collection analysis was performed between 55 and $95^{\circ} \mathrm{C}$, with $0.5^{\circ} \mathrm{C}$-increments. All data were analyzed using the iCycler IQ optical system software version 1.0 (Bio-Rad Laboratory).

\section{DNase I Inhibition Assay}

The previously described DNase I inhibition method was used without modification for G-actin and total actin quantification. ${ }^{14}$ The quantity of F-actin was derived by subtracting G-actin from total actin and thereby the ratio of F-actin to G-actin was determined.

\section{SiRNA Transfection for Annexin-I}

Three small interfering RNA (siRNA)-coding oligos against human annexin-I were synthesized and purified by Qiagen from the design tool (Qiagen). The Annexin-I mRNA sequence was derived from Gene bank NM_000700. The three annexin-I/siRNAs were: (1) 5'-TTG CAA GAA GGT AGA GAT AAA-3' (Catalog No.; SI00014259): sense, r(GCA AGA AGG UAG AGA UAA A) dTdT, antisense; r(UUU AUC UCU ACC UUC UUG C) dAdA; (2) 5'-CTG CCT TGC ATA AGG CCA TAA-3' (Catalog No.; SI00014252): sense, r(GCC UUG CAU AAG GCC AUA A) dTdT, antisense; r(UUA UGG CCU UAU GCA AGG C) dAdG; (3) 5'-TCC TAT AAG CTT AAA TAG GAA- $3^{\prime}$ (Catalog No.; SI02624174): sense; r(CUA UAA GCU UAA AUA GGA A) dTdT, antisense; r(UUC CUA UUU AAG CUU AUA G) dGdA. A fluoresce-labeled 3'-AlexaFluor 488 negative control siRNA was also generated using the following sequences: $5^{\prime}$-AAT TCT CCG AAC GTG TCA CGT3' (Catalog No. 1022563): sense, r(UUC UUC GAA CGU GUC ACG U) dTdT, antisense, r(ACG UGA CAC GUU CGG AGA A) dTdG, which was used for the detection of transfection efficiency and silencing control. The siRNA transfections of the A549 cell were performed using the HiPerFect transfection reagent kit according to the manufacturer's instructions (Qiagen, Catalog No. 301705). Briefly, A549 cells $\left(1 \times 10^{6}\right)$ were cultured in a 60 -mm culture dish as described above. SiRNA complexes in $100 \mu \mathrm{l}$ serum-free culture medium with a final siRNA concentration of $5 \mathrm{nM}$, together with $20 \mu \mathrm{l}$ of HiPerFect transfection reagent, were mixed for 5-10 min at room temperature. The transfection complexes were added to the cell culture and incubated for $24 \mathrm{~h}$. After transfection, GTE at concentrations of $0,10,20$, and $40 \mu \mathrm{g} / \mathrm{ml}$ was added. After $24 \mathrm{~h}$ incubation, cells were harvested for RT-PCR, immunoblot analysis, and immunofluorescence assay.

\section{Cell Adhesion and Migration}

For cell adhesion analysis, 96-well tissue culture plates were coated with $50-\mu \mathrm{g} / \mathrm{ml}$ fibronectin for $1 \mathrm{~h}$ at $37^{\circ} \mathrm{C}$ were used. 
After blocking with $1 \%$ bovine serum albumin for $30 \mathrm{~min}$, plates were seeded at a concentration of $5 \times 10^{4}$ cells per well with untreated cells and cells treated with GTE $(40 \mu \mathrm{g} / \mathrm{ml})$, siRNA or combination at different time points $(1,2$, and $3 \mathrm{~h})$. After washing off the nonattached cells with $1 \times$ PBS and shaking, the remaining attached cells were fixed in $1 \%$ glutaraldehyde for $15 \mathrm{~min}$, and stained with $0.1 \%(\mathrm{w} / \mathrm{v})$ crystal violet for $20 \mathrm{~min}$. Cells were lysed in 1\% SDS. The intensity of stain, in direct proportion to the number of adherent cells, was quantitated by absorbance at $595 \mathrm{~nm}$ using a microplate reader. Each cell line was tested in three separate wells over two independent experiments.

For migration assays, a uniform cell-free area was created by scratching confluent monolayers with a plastic micropipette tip as described previously. ${ }^{14}$ Briefly, the wound area was inspected at different time intervals to determine the distance migrated by the cells. The closer the gap, the faster the cell migrated. At each time point four photographs were taken and the widths of the wound space were evaluated by multiple measurements. Quantitative cell migration was performed in collagen-coated Boyden chambers (Chemicon) by removing the collagen coat in order to see the difference in GTE treated and untreated cells in migration. RPMI 1640 medium $(0.5 \mathrm{ml})$ containing $10 \%$ FBS was used in the lower Boyden chamber as the chemoattractant. A549 cells were cultured in RPMI 1640 (Mediatech) without serum and supplements for $16 \mathrm{~h}$, harvested by trypsinization, and resuspended in RPMI 1640 containing 5\% bovine serum albumin at $5 \times 10^{5}$ cells $/ \mathrm{ml}$. We placed $0.25 \mathrm{ml}$ of this cell suspension in the upper chamber and the GTE at 0 and $40 \mu \mathrm{g} / \mathrm{ml}$ concentrations at both the upper and lower chambers, respectively. The Boyden chambers were incubated overnight at $37^{\circ} \mathrm{C}$. Cells on the topside of the filter were removed, and cells that had migrated through the filter and attached to the bottom of the membrane were stained with crystal violet stain solution (Chemicon). The stain solution was eluted with $10 \%$ acetic acid extraction buffer (Chemicon) and transferred to wells of a 96-multiwell plate, and absorbance was read at $595 \mathrm{~nm}$ in each well. Experiments were repeated three times with duplicate samples.

\section{Two-Dimensional Polyacrylamide Gel Electrophoresis and Protein Identification Using Mass Spectrometry}

Two-dimensional polyacrylamide gel electrophoresis (2-D PAGE) and protein identification using mass spectrometry were performed as described previously with slight modification. ${ }^{15}$ Data represent one of the two independent analyses. Overexpressed protein spots were selected based on staining intensity of the Sypro Ruby as determined by the PDQuest software (Bio-Rad). A threefold increase in staining intensity is regarded as a significant increase in protein expression. In this study, we used this criterion to select a specific protein spot at GTE dose of $20 \mu \mathrm{g} / \mathrm{ml}$ compared to reference gel (from GTE untreated cells). Peptide sequencing was accomplished with nanoflow high performance liquid chromatography system (LC Packings, Sunnyvale, CA, USA) with a nanoelectrospray (nano-ESI) interface (Protana, Odense, Denmark) and an Applied Biosystems/Sciex QSTAR $^{\circledR}$ XL (QqTOF) mass spectrometer (Foster City, CA, USA). Protein identification was accomplished utilizing the Mascot database search engine (Matrix Science, London, UK). Positive protein identification was based on standard Mascot criteria for statistical analysis of the LC-MS/MS data. The peptide assignments in the database search results were manually inspected for validation.

\section{Statistical Analysis}

Descriptive statistics, such as mean and s.d., were used to summarize the results. The Student's $t$-tests were used for univariate analysis. Statistical significance was defined by a two-tailed $P$-value of 0.05 .

\section{RESULTS \\ GTE-Induced Annexin-I Expression Correlated with Actin Polymerization in A549 Cells}

Recently using a 2-D proteomic approach, our laboratory demonstrated that GTE induces annexin-I expression consistently in several cell models, including A549 cells. In A549 cells treated with GTE, a total of 62 spots showed differential expression ( $>$ threefold difference), and 54 proteins with unique IDs were identified, among them including annexin-I. A portion of Sypro Ruby stained 2-D PAGE gel showing the region containing the annexin-I protein is shown in Figure 1a. The protein spot with observed molecular weight of $35 \mathrm{kDa}$ and isoelectric point of 6.6 was identified as annexin-I by LC/MS/MS. To further confirm the observation, we examined the expression of annexin-I by using Western blot (Figure 1b), RT-PCR (Figure 1c), and the immunofluorescence (Figure 1d) analyses. A dose-response increase in expression pattern of annexin-I in response to GTE treatment was observed at both protein (Figure $1 \mathrm{~b}$ and $\mathrm{d}$ ) and mRNA levels (Figure 1d), implying that the GTE-induced annexin-I upregulation occurs at the transcription level. Figure $1 \mathrm{~b}$ also showed the effect of GTE on annexin-I expression in other lung cancer cell lines by Western blot, including a squamous cell carcinoma cell line H157 and a large cell carcinoma cell line H460; both cell lines appeared to be less sensitive to GTE-induced annexin-I expression, whereas increased expressions were seen in a higher dose level $(40 \mu \mathrm{g} / \mathrm{ml})$. Thus, A549 cells were used for the following experiments.

Annexin-I as one of the isoforms of annexin plays an important role in actin polymerization. ${ }^{20}$ Since previously we observed a profound stimulatory effect of GTE on actin polymerization, ${ }^{14}$ we hypothesized that GTE-induced actin remodeling might be associated with annexin-I upregulation. To test this hypothesis, we first analyzed the association of annexin-I expression and F-actin using triple-labeling immunofluorescence. Figure 1d shows a triple-labeling immunofluorescence for annexin-I (red fluorescence), F-actin 
b

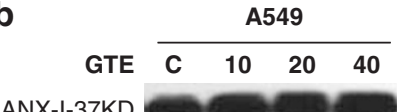

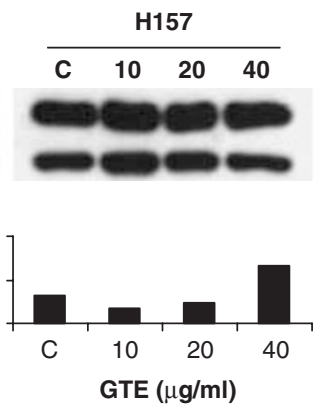

10

e
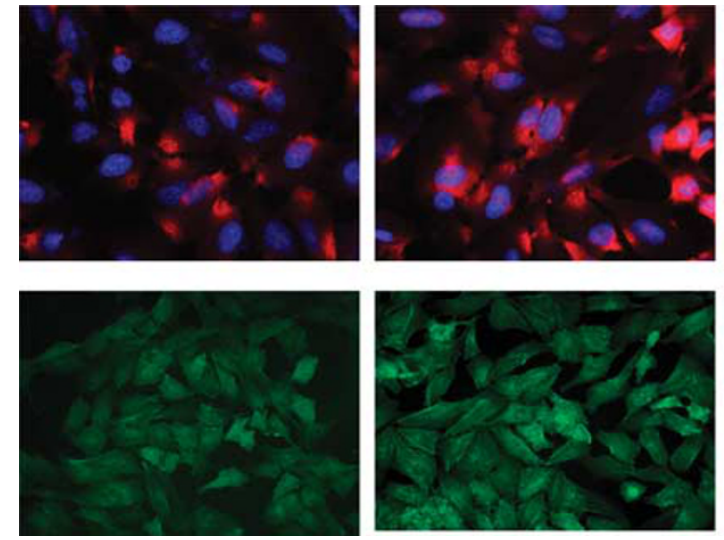

CTRL
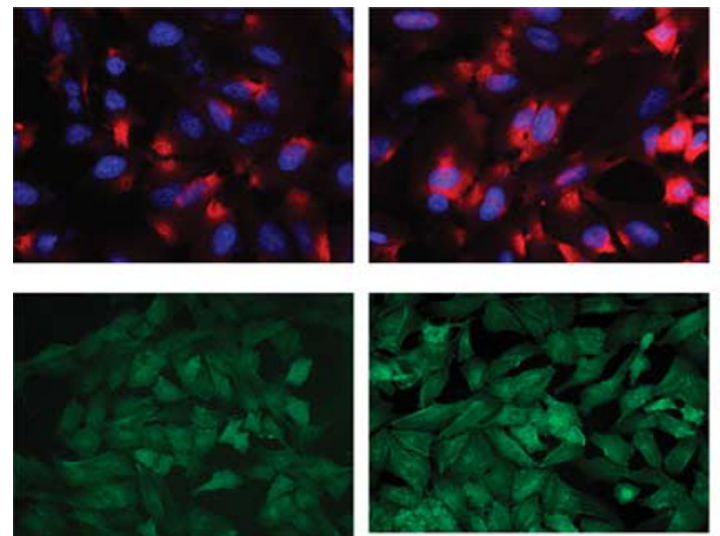

H460
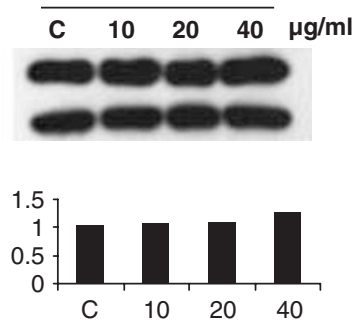

C

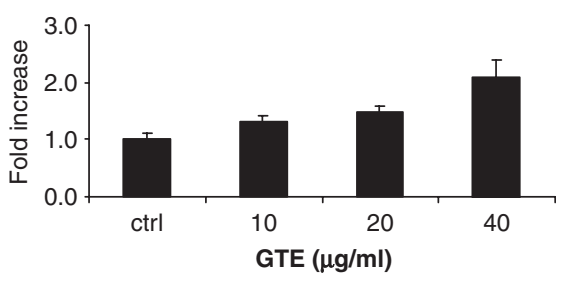

40 GTE $(\mu \mathrm{g} / \mathrm{ml})$
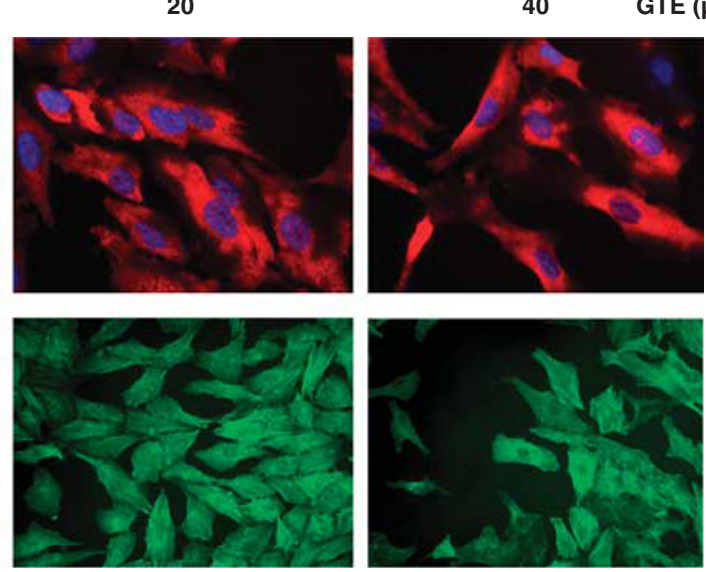

Figure 1 Dose effect of GTE on annexin-I expression and actin cytoskeleton. (a) Portion of a Sypro Ruby stained 2-D PAGE gel showing the region containing the annexin-I protein spots separated by isoelectric point (pl) in the first dimension and by molecular weight (MW) in the second dimension. 2-D PAGE and protein identification are described in the Materials and methods section. (b) Western blot analysis of annexin-I expression relative to $\beta$-actin in A549, H157, and H460 cells treated with $0,10,20$, and $40 \mu \mathrm{g} / \mathrm{ml}$ of GTE for $24 \mathrm{~h}$; Graph shows the densitometry measurement of annexin-I level relative to $\beta$-actin level. Data represent one of the two independent experiments. (c) RT-PCR analysis of annexin-I expression relative to $\beta$-actin in A549 cells treated with different concentrations of GTE $(0,10,20$, and $40 \mu \mathrm{g} / \mathrm{ml}$ ) for $24 \mathrm{~h}$. Graph represents the mean \pm s.d. of three independent experiments. (d) Immunofluorescence analysis of annexin-I in A549 cells treated with 0, 10, 20, and $40 \mu \mathrm{g} / \mathrm{ml}$ of GTE for $24 \mathrm{~h}$ were washed, fixed, and labeled sequentially for annexin-I (red fluorescence), DNA (blue fluorescence) and F-actin (green fluorescence, data not shown); (e) Immunofluorescence of F-actin (green fluorescence) in A549 cells tripled labeled with F-actin, annexin-I, and DNA as described in (d). Note that the GTE treated-A549 cells had an increased F-actin staining intensity. Images were taken using a Nikon Eclipse E400 microscope at $\times 40$ object.

(green fluorescence), and DNA (blue fluorescence) in GTE treated $(10,20$, and $40 \mu \mathrm{g} / \mathrm{ml}$ ) and untreated (control) A549 cells. GTE treated cells displayed an increase of F-actin staining and filaments formation in a dose-dependent manner, with concomitant increase of annexin-I level. The finding suggests GTE-induced annexin-I overexpression may play a role in actin remodeling.

\section{Annexin-I Upregulation is Essential for GTE-Induced F-Actin Polymerization}

To determine the role of GTE induced annexin-I in actin remodeling, siRNA experiments were performed. As expected, GTE alone $(20 \mu \mathrm{g} / \mathrm{ml})$ enhanced F-actin fluorescence intensity (green), with a concomitantly increased annexin-I staining intensity (red) (Figure 2a). Cells exposed to annexin-I -specific siRNA complexes in the absence and presence of GTE displayed a decreased F-actin fluorescence intensity (green). As another level of control, cells exposed to negative control complex siRNA(-) and GTE together showed an increased F-actin and annexin-I fluorescence intensities similar to GTE alone treated cells. Western blot and RT-PCR analyses confirmed the effect of GTE on stimulating annexinI expression at mRNA level (Figure $2 b$ and $c$ ). Cells treated with GTE alone had a dose-response increase of annexin-I expression. Cells treated with siRNA complex resulted in a reduced expression of annexin-I, which also blocked the GTE-induced annexin-I expression. These data together strongly support the hypothesis that GTE stimulates annexinI expression, which results in an increased actin polymerization in cultured lung adenocarcinoma cells. 
a
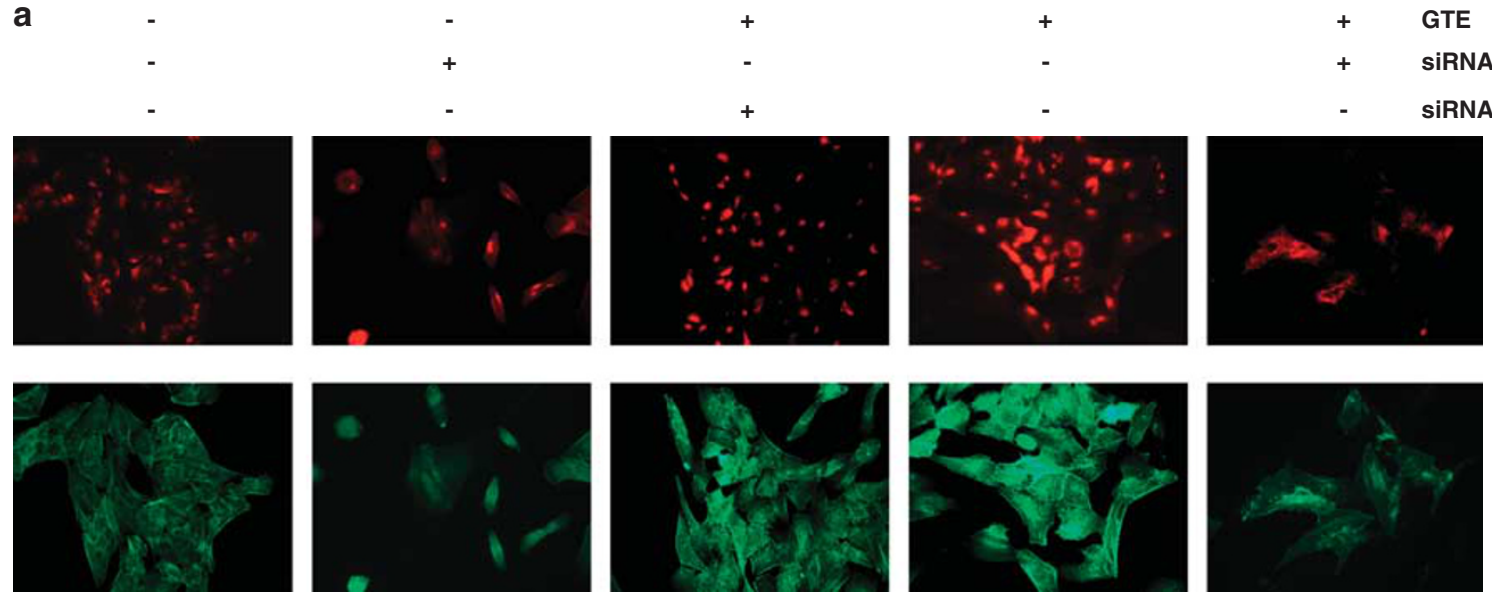

ANX-I
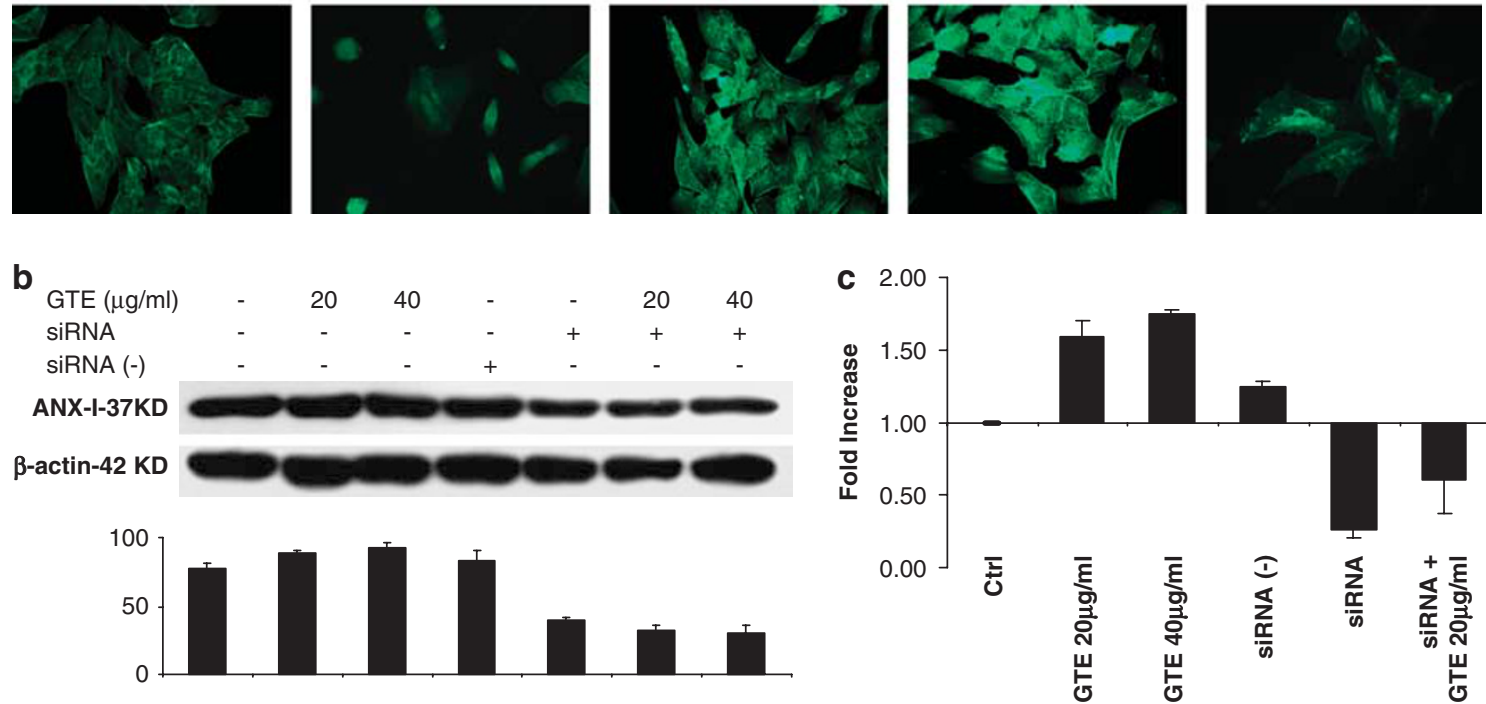

F-actin

Figure 2 Effect of annexin-I RNA interference on annexin-I and F-actin in GTE treated cells. The procedures for RNA interference and immunofluorescence labeling are described in the Materials and methods section. (a) Images of fluorescence labeling of annexin-I (red fluorescence) and F-actin (green fluorescence) under various conditions as specified. As expected, siRNA blocks the GTE ( $20 \mu \mathrm{g} / \mathrm{ml})$ induced annexin-I expression (red), which resulted in a decreased F-actin (green), as observed by comparing images of annexin-I and F-actin in cells treated with GTE without siRNA to the images with siRNA. As a comparison, siRNA with negative control (siRNA(-)) complex had no such an effect (ie, increased F-actin and annexin-I with GTE). Images were taken using a Nikon Eclipse E400 microscope at $\times 20$ object. Confirmation of differential expression of annexin-I in A549 cell lines treated with GTE by (b) Western blot results of conditions as specified. Bar graph represents mean \pm s.d. of densitometry measurements of annexin- 1 relative to $\beta$-actin in two independent experiments. (c) Quantitative real-time PCR analysis of annexin-I expression under various conditions as specified. Bar graph in (b) shows the densitometry result of annexin-I relative to $\beta$-actin, and in (c) shows mean \pm s.d. of three independent experiments.

To quantitatively analyze the effect of GTE-induced annexin-I expression on actin polymerization, two different methods were used: the biochemical-based DNase I inhibition assay (for F/G-actin ratio) and fluorescence-based LSC analysis (for F-actin fluorescence intensity), and the results were presented in Figure 3. After incubation for $24 \mathrm{~h}$, GTE at $40 \mu \mathrm{g} / \mathrm{ml}$ dosage induced actin polymerization, as indicated by increased $\mathrm{F} / \mathrm{G}$ ratio (Figure 3a) and F-actin intensity (Figure $3 \mathrm{~b}$ ) comparing to the untreated control. However, incubation of cells with annexin-I siRNA showed markedly decreased F/G-ratio (Figure 3a) and F-actin intensity (Figure $3 \mathrm{~b})$ relative to GTE only treated cells. The GTE induced-actin polymerization was not affected by siRNA negative control $(\operatorname{siRNA}(-))$ (Figure 3a). However, compared to untreated control, F-actin intensity was slightly increased with siRNA complex even without GTE (Figure 3b). These findings confirm the effect of GTE-induced annexin-I expression on stimulating actin polymerization.

\section{GTE Increased Adhesion and Decreased Migration in A549 Cells}

Because actin plays an important role in tumor cell adhesion and motility and presumably tumor cell invasion, we tested the effect of GTE on cell adhesion in A549 cells, comparing GTE treated and untreated cells. GTE treatment $(40 \mu \mathrm{g} / \mathrm{ml})$ significantly $(P<0.01)$ enhanced cell adhesion in A549 cells on a fibronectin-coated surface relative to the untreated control (Figure 4a). Again, annexin-I specific interference by siRNA was used to determine if annexin-I is involved in the GTE-induced cell adhesion. As shown in Figure 4a, GTEinduced increase in cell adhesion was blocked by annexin-I specific siRNA interference, whereas negative control siRNA had no effect.

To further assess the involvement of GTE induced adhesion change in A549 cells, we stained paxillin, a marker for cell adhesion complex. Control A549 cells displayed few adhesion complex at the cell periphery. Cells treated with GTE, 
a

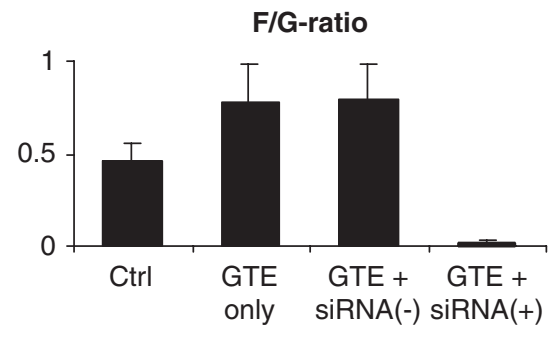

b F-actin Fluorescence Intensity

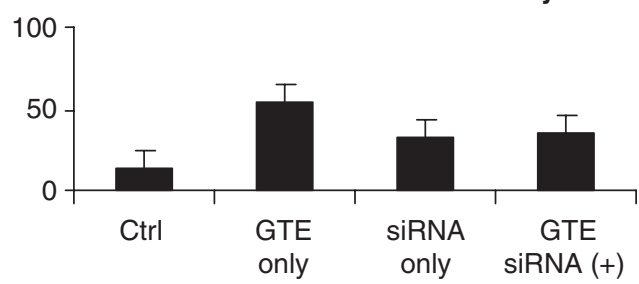

Figure 3 Effect of GTE on actin polymerization in A549 cells. (a) Effect of GTE on F-actin to G-actin ratio. Cells exposed to GTE ( 0 and $40 \mu \mathrm{g} / \mathrm{ml})$ with or without siRNA annexin-I transfection for $24 \mathrm{~h}$ were harvested and the F/ G-ratio increment were determined by DNase I inhibition assay as described in the Materials and methods section. The F- to G-actin ratio was calculated as the percentage of increase of F/G-ratio in treated sample $v$ s the paralleluntreated control sample (ie, (sample F/G-ratio - control F/G-ratio)/ control F/G-ratio $\times 100 \%$ ). Data represent one of the two independent experiments. (b) Effect of GTE on F-actin. Cells treated with $40 \mu \mathrm{g} / \mathrm{ml}$ of GTE for $24 \mathrm{~h}$ with or without siRNA annexin-I transfection on cover glass underwent F-actin fluorescence intensity analysis by LSC. About 1000-2000 cells were measured for each condition. Bar graph represents the mean \pm s.d. of cells analyzed.

however, displayed markedly increased adhesion complex formations. Annexin-I specific siRNA resulted in a decrease in adhesion complex formation (Figure 4b). These findings suggest annexin-I is involved in the regulation of adhesive activity of lung adenocarcinoma cells.

Figure 5a shows the effect of GTE on cell motility utilizing wound-scratch assay with annexin-I being blocked. The migration of A549 cells treated with $40 \mu \mathrm{g} / \mathrm{ml}$ GTE for $24 \mathrm{~h}$ was significantly inhibited compared to untreated control $(P<0.05)$. The inhibitory effect of GTE was further confirmed using a chemotaxi cell chamber (Figure $5 b$ ). In this assay, A549 cells were cultured in a double-chambered well, where they were allowed to migrate, penetrate the filter separating the chambers, and to enter the lower chamber without collagen cap. The OD values were 1.07 and 0.13 , in untreated control $(0 \mu \mathrm{g} / \mathrm{ml}$ for $24 \mathrm{~h}) v s$ cells GTE-treated cells $(40 \mu \mathrm{g} / \mathrm{ml}$ for $24 \mathrm{~h})$, respectively, indicating the inhibitory effect of GTE on cell invasion. It should be noted with the collagen coat left on the chamber, no migration was seen in either control or GTE treated cells, suggesting that A549 cells may either have impaired collagen related signaling pathway, or collagen has inhibitory, rather than stimulatory effect on A549 cell migration.

It was also interesting to note that annexin-I specific siRNA interference resulted in decreased cell motility in A549 cell even without GTE treatment (Figure 5a). The finding might suggest that a balanced level of annexin-I expression is needed for cell migration. Alternatively, it is possible that other factors in addition to annexin-I may be involved in motility regulation of A549 cells, and inhibition of annexin-I expression may somehow paradoxically alter the expression of these factors.

\section{DISCUSSION}

The GTE used in this study is similar to Polyphenone E (80-98\% total catechin by weight), used in NCI-supported green tea clinical trials. The decaffeinated extract consists of $84 \%$ total catechin by weight, measured by high-performance liquid chromatography. ${ }^{21}$ Other reported minor components that may be present in the GTE include non-esterifed or esterified gallic acid, $3^{\prime}$-O-methyl EC, and EGC. Flavonols, including quercetin, kaempferol, myricitin, and their glycosides, theasinensins, which are dimeric gallocatechins (GC) linked by $\mathrm{C}-\mathrm{C}$ bonds, nitrogenous material as protein, amino and nucleic acid and minerals such as $\mathrm{K}, \mathrm{Ca}, \mathrm{Mg}$, and $\mathrm{Al}$, are also the constituents of green tea. ${ }^{6}$ It is possible that a large diversity of structures present in green tea contributes to its multiple chemopreventive activities.

The current study demonstrates that green tea induces annexin-I expression and actin remodeling in lung adenocarcinoma cells. The increased expression of annexin-I induced by GTE correlates with the stimulation of F-actin polymerization, which in turn results in the increase of cell adhesion in A549 cells. Green tea also decreases cell motility. Cytoskeletal actin is a ubiquitous protein present in all eukaryotic cells. ${ }^{22}$ The cytoskeletal network is mainly composed of actin filaments, microtubules, intermediate filaments, and accessory proteins. As one of the major proteins in the cell, actin and its associated proteins play an important structural and functional roles, such as maintaining cell morphology, cell adhesion, cell motility, exo and endocytosis, and cell division. ${ }^{23-28}$ Previous studies have focused on the actin cytoskeleton as a governing element of cell motility and as a dynamic target for cancer chemotherapy. ${ }^{29-31}$ It has also been postulated that actin may function as an important mediator between oncogenic signal transduction activities and malignant phenotypes. ${ }^{32,33}$ Our findings may provide another mechanism in explaining the antitumor effect of GTE.

Previous studies from this laboratory and others have provided ample evidence that actin remodeling is a dynamic process in malignant transformation, in that in the early stage of cancer development actin is depolymerized, which is accompanied by cellular-dedifferentiation and loss of adhesion. ${ }^{34}$ At a later stage, the tumor cells may regain the actin polymerization capability through the activation of Ras superfamily GTPase (Rac/Rho/CDC42) that causes re-distribution of actin filaments in a way favoring cellular movement and migration. ${ }^{14}$ Although the actin polymerization has been viewed as a necessary event for cell motility, it 
a
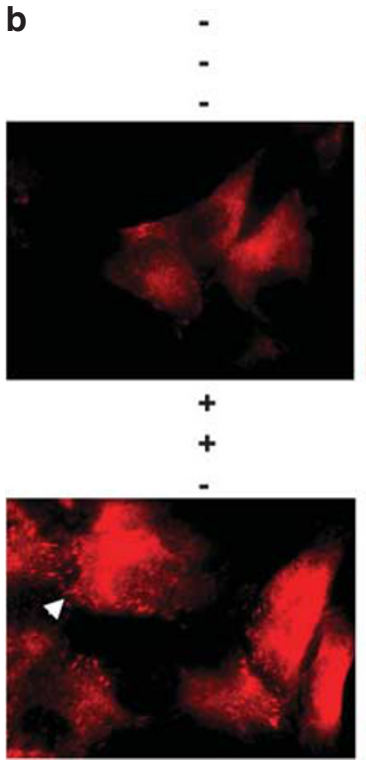
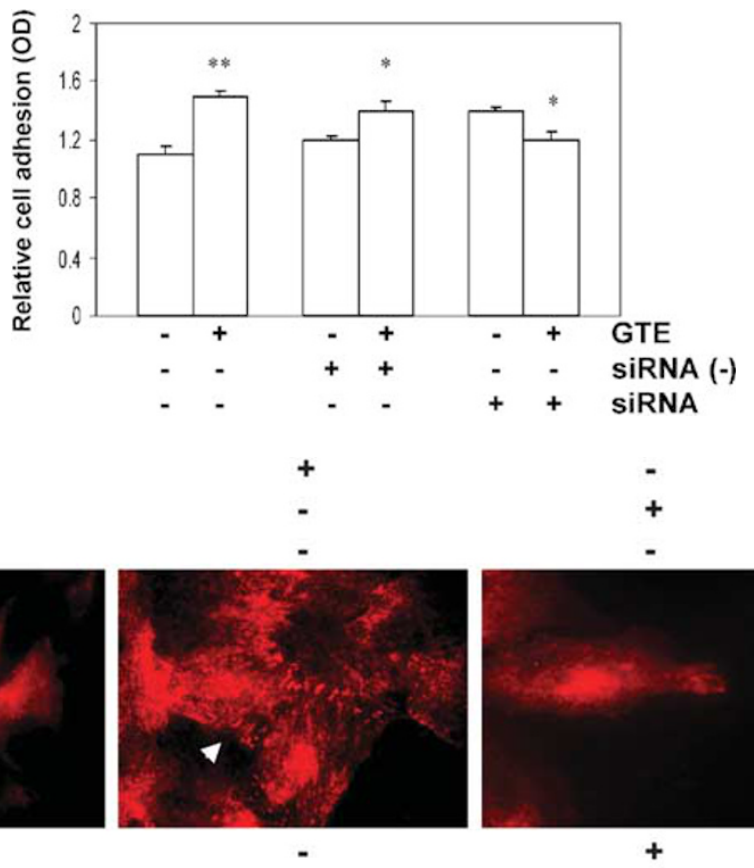

$+$

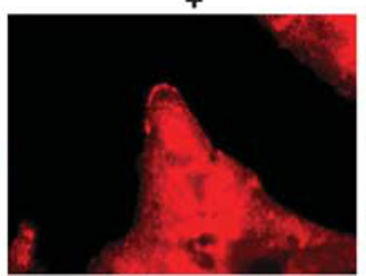

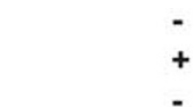

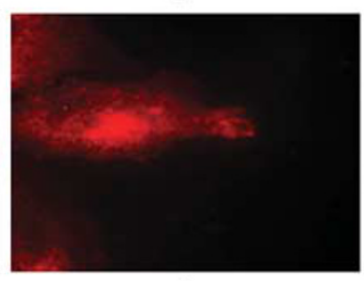

$+$

$-$

$+$

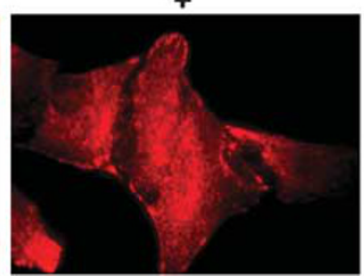

Figure 4 Effects of GTE on (a) adhesion and (b) adhesion complex formation in A549 cells. (a) Cells growing on fibronectin-coated culture plates for $2 \mathrm{~h}$ were fixed with glutaraldehyde, stained with crystal violet, and measured by a microplate reader, as detailed in the Materials and methods section. Cells treated without or with GTE $(40 \mu \mathrm{g} / \mathrm{ml})$, siRNA, or combination for $24 \mathrm{~h}$ under various conditions as specified. Note that GTE increased adhesion significantly. Values represent one of two independent experiments. ${ }^{*} P<0.01,{ }^{*} P<0.05$. (b) Immunofluorescence analysis of paxillin in A549 cells treated with $40 \mu \mathrm{g} / \mathrm{ml}$ of GTE for $24 \mathrm{~h}$ were washed, fixed, and labeled with paxillin (red fluorescence), as detailed in the Materials and methods section. Images were taken using a Nikon Eclipse E400 microscope at $\times 40$ object. The white arrowhead indicates the focal adhesion complex. has been shown that the distribution of actin filaments, rather than the net actin polymerization, may be more important in determining cellular adhesion and motility, at least in epithelial cells. This hypothesis is supported by our previous study in urothelial cells, in that when GTE induced actin polymerization and distribution in a peripheral rather than pointed manner as 4-aminobiphenyl did, the cell adhesion increases, which results in a reduced, rather than increased, cellular motility. ${ }^{14}$ The current findings from lung adenocarcinoma A549 cells also support this view. We are currently undergoing studies using atomic force microscopy to further define the structural/functional relationship between actin remodeling and cell adhesion/motility in GTE treated and untreated cells. Future study will examine whether Rho proteins, including CDC42, Rac1, and RhoA, are required for annexin-I-mediated F-actin formation, cell adhesion, and motility in lung adenocarcinoma cells.

Annexins are a family of structurally related proteins that exhibit $\mathrm{Ca}^{2+}$-dependent binding to anionic phospholipids. They are either found free in the cytosol or associated with membranes of various cell types and tissues including the lung. Annexin-I is the first of 13 members in the family and is involved in many biological functions such as cell differ- entiation, $^{35}$ anti-inflammation, ${ }^{36}$ apoptosis, ${ }^{37}$ and cell growth, ${ }^{17}$ and acts as a stress protein. ${ }^{38}$ Annexin-I has been studied for its role in stimulating actin polymerization. Although the roles of annexin-I in actin dynamics are not fully understood mechanically, it has been shown that annexin-I binds and bundles actin filaments in a $\mathrm{Ca}^{2+}$ dependent manner, and may also influence actin polymerization by binding to phospholipids and profilin. ${ }^{39}$ It has also been found that the addition of glucocorticoid, an anti-inflammatory agent, to A549 cells results in annexin-I translocation to the membrane compartment and subsequent externalization: the membrane-bound protein inhibited prostaglandin release by affecting cytosolic phospholipase $\mathrm{A}_{2}$ activation through an effect of epidermal growth factor signaling, thereby blocking cell proliferation. ${ }^{17,40}$ Although our study shows a direct effect of annexin-I expression in actin remodeling in response to GTE, one cannot exclude the possibility of such an observed effect being a secondary event, for example, as the result of cellular anti-inflammatory response as observed for glucocorticoid. Whereas annexin-I specific RNA interference blocks the GTE-induced actin polymerization and adhesion, the effect of such interference on cell motility is complicated by the finding that siRNA 

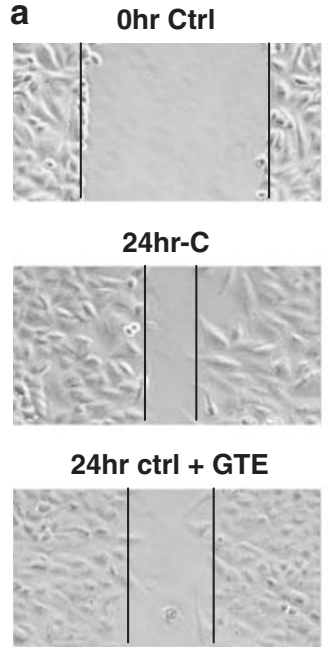

Ohr siRNA (-)

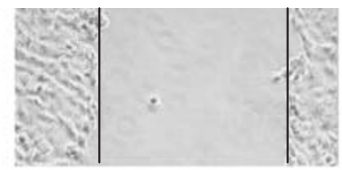

24hr siRNA (-)

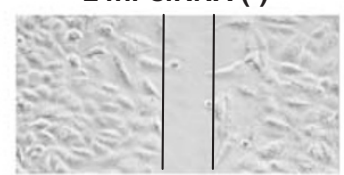

24hr GTE + siRNA (-)

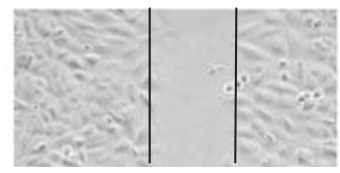

Ohr siRNA (+)

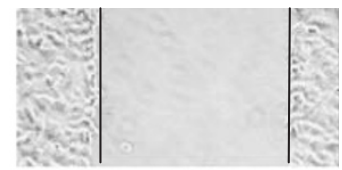

24hr siRNA (+)

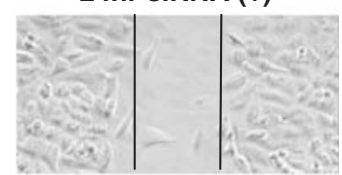

24hr GTE + siRNA (+)

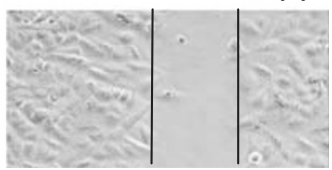

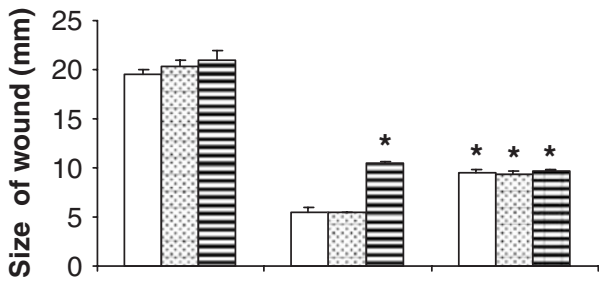

3

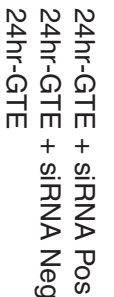

b

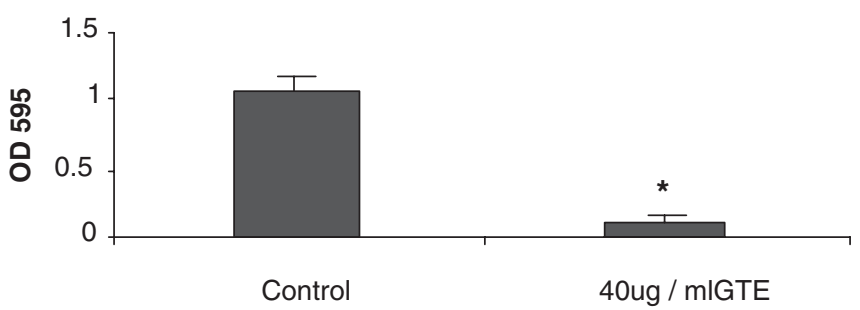

Figure 5 Effects of GTE on the migration of A549 cells. (a) Confluent monolayers of cells were maintained in a serum-free media, and a lane was scraped through the monolayers of the cells with a plastic micropipette tip. The cells were allowed to migrate across the lane at $37^{\circ} \mathrm{C}$ for $24 \mathrm{~h}$ in the presence ( $40 \mu \mathrm{g} /$ $\mathrm{ml}$ ) or absence of GTE with or without siRNA annexin-I transfection for $24 \mathrm{~h}$. The distance that cells migrated into the area of the wound at different points was photographed using a computer imaging system. Data represent one of three independent experiments. (b) A549 cells were incubated with $40 \mu \mathrm{g} / \mathrm{ml}$ of GTE in the top chamber for $24 \mathrm{~h}$. The number of cells that migrated through the filter to the lower surface was counted, as determined by OD measurement using a microplate reader. The results are the mean \pm s.d. of two different fields $\left({ }^{*} P<0.05\right)$.

itself, even without GTE, also inhibits the cell motility. The mechanism for that is not clear. One possible explanation is that a balanced level of annexin-I expression is needed for cell migration. There may be an optimal concentration for annexin-I and F-actin polymerization to promote migration, a phenomenon similar to adhesion receptors observed previously, with low concentrations of adhesion receptors failing to provide traction, high concentrations leading to increased adhesion, and moderate concentrations appropriate for migration. ${ }^{41}$ Inhibition of annexin-I expression by siRNA may result in decreased actin polymerization and motility, whereas overexpression of annexin-I by GTE may cause actin overpolymerization, which also reduces cell motility, probably owing to the increased adhesion (or traction) of the cells to the culturing stratum. Alternatively, it is possible that other factors in addition to annexin-I may be involved in motility regulation of A549 cells, and inhibition of annexin-I expression may somehow paradoxically alter the expression of these factors. Further studies are needed to investigate the mechanisms underlying this unexpected intriguing finding.

In summary, the above experiments show that GTE stimulates annexin-I expression in A549 cells. GTE stimulates actin polymerization resulting in an increased cell adhesion that is mediated by annexin-I. GTE also inhibits A549 cell motility. Our studies have demonstrated for the first time, to our knowledge, that A549 cells responded to GTE with increased annexin-I protein, which provided a novel mechanism for the antitumor effect of green tea. Annexin-I may provide a marker for GTE-based therapy.

\section{ACKNOWLEDGEMENT}

This has been supported by a research grant from the UCLA Lung Cancer SPORE (NIH Grant No. P50 CA90833), Jonsson Comprehensive Cancer

Center Alper Grant and the Starr Foundation. We are grateful to Pharmanex Inc. for providing us with the source of green tea extract, and Esther He and Aya Westbrook for providing technical support.

1. ACS. 2006 Cancer Statistics, http://www.cancer.org, 2006.

2. Tsao AS, Kim ES, Hong WK. Chemoprevention of cancer. CA Cancer J Clin 2004;54:150-180.

3. Cohen V, Khuri FR. Progress in lung cancer chemoprevention. Cancer Control 2003;10:315-324.

4. Lambert JD, Yang CS. Cancer chemopreventive activity and bioavailability of tea and tea polyphenols. Mutat Res 2003;523-524: 201-208.

5. Surh YJ. Cancer chemoprevention with dietary phytochemicals. Nat Rev Cancer 2003;3:768-780.

6. Yang CS, Maliakal P, Meng X. Inhibition of carcinogenesis by tea. Annu Rev Pharmacol Toxicol 2002;42:25-54.

7. Tewes FJ, Koo LC, Meisgen TJ, et al. Lung cancer risk and mutagenicity of tea. Environ Res 1990;52:23-33. 
8. Zhong L, Goldberg MS, Gao YT, et al. A population-based case-control study of lung cancer and green tea consumption among women living in Shanghai, China. Epidemiology 2001;12:695-700.

9. Imai K, Suga K, Nakachi K. Cancer-preventive effects of drinking green tea among a Japanese population. Prev Med 1997;26:769-775.

10. Ohno Y, Wakai K, Genka K, et al. Tea consumption and lung cancer risk: a case-control study in Okinawa, Japan. Jpn J Cancer Res 1995;86:1027-1034

11. Zheng W, Doyle TJ, Kushi LH, et al. Tea consumption and cancer incidence in a prospective cohort study of postmenopausal women. Am J Epidemiol 1996;144:175-182.

12. Nagano J, Kono S, Preston DL, et al. A prospective study of green tea consumption and cancer incidence, Hiroshima and Nagasaki (Japan). Cancer Causes Control 2001;12:501-508.

13. Koo LC. Dietary habits and lung cancer risk among Chinese females in Hong Kong who never smoked. Nutr Cancer 1988;11:155-172.

14. Lu QY, Jin YS, Pantuck A, et al. Green tea extract modulates actin remodeling via Rho activity in an in vitro multistep carcinogenic model. Clin Cancer Res 2005;11:1675-1683.

15. Xiao GS, Jin YS, Lu QY, et al. Annexin-I as a potential target for green tea extract induced actin remodeling. Int J Cancer 2006;120: 111-120.

16. Di Rosa M, Flower RJ, Hirata F, et al. Anti-phospholipase proteins. Prostaglandins 1984;28:441-442.

17. Croxtall JD, Flower RJ. Lipocortin 1 mediates dexamethasone-induced growth arrest of the A549 lung adenocarcinoma cell line. Proc Nat Acad Sci USA 1992;89:3571-3575.

18. Kang JS, Calvo BF, Maygarden SJ, et al. Dysregulation of annexin I protein expression in high-grade prostatic intraepithelial neoplasia and prostate cancer. Clin Cancer Res 2002;8:117-123.

19. Mao JT, Tsu IH, Dubinett SM, et al. Modulation of pulmonary leukotriene B4 production by cyclooxygenase-2 inhibitors and lipopolysaccharide. Clin Cancer Res 2004;10:6872-6878.

20. Hayes MJ, Rescher U, Gerke V, et al. Annexin-actin interactions. Traffic 2004:5:571-576.

21. Sartippour MR, Heber D, Ma J, et al. Green tea and its catechins inhibit breast cancer xenografts. Nutr Cancer 2001:40:149-156.

22. Weber K, Lazarides $\mathrm{E}$, Goldman RD, et al. Localization and distribution of actin fibers in normal transformed and revertant cells. Cold Spring Harb Symp Quant Biol 1975;39(Part 1):363-369.

23. Pollard TD, Cooper JA. Actin and actin-binding proteins. A critical evaluation of mechanisms and functions. Annu Rev Biochem 1986;55:987-1035.
24. Singer SJ. Intercellular communication and cell-cell adhesion. Science 1992;255:1671-1677.

25. Hitt AL, Luna EJ. Membrane interactions with the actin cytoskeleton. Curr Opin Cell Biol 1994;6:120-130.

26. Olson MF, Ashworth A, Hall A. An essential role for Rho, Rac, and Cdc42 GTPases in cell cycle progression through G1. Science 1995;269: $1270-1272$.

27. Nobes CD, Hall A. Rho, rac, and cdc42 GTPases regulate the assembly of multimolecular focal complexes associated with actin stress fibers, lamellipodia, and filopodia. Cell 1995;81:53-62.

28. Luna EJ, Hitt AL. Cytoskeleton-plasma membrane interactions. Science 1992:258:955-964.

29. Pantaloni D, Le Clainche C, Carlier MF. Mechanism of actin-based motility. Science 2001;292:1502-1506.

30. Stossel TP. On the crawling of animal cells. Science 1993;260: 1086-1094.

31. Jordan MA, Wilson L. Microtubules and actin filaments: dynamic targets for cancer chemotherapy. Curr Opin Cell Biol 1998;10:123-130.

32. Turner CE. Paxillin interactions. J Cell Sci 2000;113:4139-4140.

33. Turner CE. Paxillin. Int J Biochem Cell Biol 1998;30:955-959.

34. Rao J, Li N. Microfilament actin remodeling as a potential target for cancer drug development. Curr Cancer Drug Targets 2004:4:345-354.

35. Solito $E$, de Coupade $C$, Parente $L$, et al. Human annexin 1 is highly expressed during the differentiation of the epithelial cell line A 549: involvement of nuclear factor interleukin 6 in phorbol ester induction of annexin 1. Cell Growth Differ 1998;9:327-336.

36. Parente $\mathrm{L}$, Solito E. Annexin 1: more than an anti-phospholipase protein. Inflamm Res 2004;53:125-132.

37. Sakamoto T, Repasky WT, Uchida K, et al. Modulation of cell death pathways to apoptosis and necrosis of $\mathrm{H}_{2} \mathrm{O}_{2}$-treated rat thymocytes by lipocortin I. Biochem Biophys Res Commun 1996;220:643-647.

38. Rhee HJ, Kim GY, Huh JW, et al. Annexin I is a stress protein induced by heat, oxidative stress and a sulfhydryl-reactive agent. Eur J Biochem 2000;267:3220-3225.

39. Alvarez-Martinez MT, Mani JC, Porte F, et al. Characterization of the interaction between annexin I and profilin. Eur J Biochem 1996:238:777-784.

40. Croxtall JD, Flower RJ. Antisense oligonucleotides to human lipocortin1 inhibit glucocorticoid-induced inhibition of A549 cell growth and eicosanoid release. Biochem Pharmacol 1994;48:1729-1734.

41. DiMilla PA, Stone JA, Quinn JA. Maximal migration of human smooth muscle cells on fibronectin and type IV collagen occurs at an intermediate attachment strength. J Cell Biol 1993;122:729-737. 